\title{
Continuous Positive Airway Pressure in Preterm Neonates: An Update of Current Evidence and Implications for Developing Countries
}

\author{
"Neeraj Gupta, *Shiv Sajan Saini, \$SRinivas Murki,*Praveen Kumar and ₹Ashok Deorari \\ Departments of Pediatrics, ${ }^{*}$ AIIMS Jodhpur; *PGIMER, Chandigarh; ${ }^{\$}$ Fernandez Hospital Hyderabad and ${ }^{\ddagger}$ AIIMS, New Delhi, \\ India. \\ Correspondence to: Dr Praveen Kumar, Professor, Neonatal Unit, Department of Pediatrics, Advanced Pediatric Center, Post \\ Graduate Institute of Medical Education and Research (PGIMER), Chandigarh 160 012, India. drpkumarpgi@gmail.com \\ Received: September 30, 2014; Initial review: December 30, 2014; Accepted: January 29, 2015.
}

Context: Continuous Positive Airway Pressure (CPAP) is a cost-effective and minimal invasive respiratory support for the newborn. Objective: To review the evidence related to various aspects of CPAP usage and its applicability for developing countries.

Evidence Acquisition: We conducted a literature search on PubMed, CENTRAL, and Cochrane Database of Systematic Reviews using the terms 'CPAP' OR 'continuous positive airway pressure' OR, non-invasive ventilation' AND 'newborn' OR 'neonate' OR 'infant'. We also searched the reference lists from the above articles and of review articles. Extracted manuscripts and reviews were analyzed and results related to various aspects of CPAP usage were summarized in narrative form.

Results: Early use of CPAP with early rescue surfactant (InSurE) is the ideal approach for management of respiratory distress syndrome in preterm and extremely preterm infants. Delivery room CPAP is feasible and reduces the need for surfactant and mechanical ventilation by nearly $50 \%$. Prophylactic surfactant for extreme preterms should be discouraged. Heated humidified high flow nasal cannula is best utilized for post-extubation respiratory support. The search for ideal interface still continues and binasal prongs or nasal masks are the good contenders. Evidence on the ideal CPAP delivery is still inconclusive.

Conclusions: CPAP, if used early and judiciously, is an effective intervention and need immediate scaling-up in resource-limited settings. Future research should focus on the ideal interface and the CPAP delivery methods.

Keywords: Continuous positive airway pressure, Mechanical ventilation, Noninvasive ventilation, Neonate.

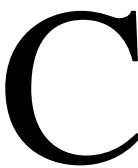

ontinuous Positive Airway Pressure (CPAP) is a well-established mode of respiratory support in preterm newborns. Advancement in technology, increasing survival of extremely preterm newborns and better understanding of various respiratory diseases led to new evidence in this field over last decade. It is important to update ourselves on the recent changes in the practice of CPAP and its implications for resource-limited settings.

We reviewed evidence for the clinical use of CPAP as a primary treatment for respiratory distress syndrome (RDS), delivery room CPAP, CPAP generator, heated humidified high flow nasal cannula (HHHFNC) and CPAP interface in neonates.

\section{EVidence on Clinical Use}

\section{Primary Treatment of RDS}

CPAP vs no CPAP (Hood oxygen): Meta-analysis evaluating CPAP against head box oxygen showed that CPAP use reduced the overall rate of mortality [RR 0.52 (95\% CI 0.32, 0.87)] and the rate of the combined outcome of death or assisted ventilation [RR 0.70 (95\% CI 0.55, 0.88)]. However, there was increased risk of pneumothorax [RR 2.64 (95\% CI 1.39, 5.04); NNH 17 $(17,25)][1]$. Use of CPAP has also shown to decrease the need for up-transfers to higher centers [2]. The introduction of CPAP in a level II special newborn care unit significantly reduced the need for up-transfers as compared to pre-CPAP epoch, especially in very low birth weight (VLBW) and preterm infants [3].

Early vs late CPAP: The application of CPAP early in the course of the disease before alveolar collapse occurs may work better than late CPAP by reducing lung damage and promoting lung function and surfactant pool. In the systematic review that compared early CPAP (starting CPAP at the time of randomization) vs. late CPAP (initiating late in the course of disease when $\mathrm{FiO}_{2}$ requirement is $>0.60$ ), early CPAP was associated with a significant reduction in subsequent use of mechanical ventilation [RR 0.55, (95\% CI 0.32, 0.96); NNT 6]. But early CPAP had no effect on overall mortality, bronchopulmonary dysplasia (BPD) or pneumothorax [4].

Delivery room/very early CPAP: The conventional approach of managing extreme premature infants was intubation, surfactant administration and mechanical 
ventilation. Gradually it was realized that both CPAP and surfactant lead to the same final goal of establishing functional residual capacity. Recently CPAP has been used to stabilize neonates immediately after resuscitation in the delivery room. Three high-quality randomized controlled trials compared delivery room CPAP (DR CPAP or prophylactic CPAP) with conventional approach [5-7] (Table I). When used early in the delivery room in extreme preterm infants (gestation $<28$ weeks), either prophylactic [6,7] or early rescue [5], CPAP was associated with almost 50\% reduction in need for intubation mechanical ventilation, and surfactant usage in comparison to 'mechanical ventilation with or without surfactant'. The risk of death or BPD at 36 weeks was comparable between the two treatment approaches in these trials. Thus it is clear that initial stabilization on CPAP and provision of rescue surfactant should be the preferred approach among preterm neonates $\leq 28$ weeks of gestation.

CPAP and surfactant (InSurE strategy): CPAP and surfactant work together towards establishing and maintaining functional residual capacity in RDS. Verder, et al. [9] described a technique, InSurE (Intubation,

TABLE I: Studies Comparing DeliVery RoOM CPAP or Prophylactic CPAP With CONVENTIONAL ApProAch

\begin{tabular}{ll}
\hline Author & Study design and population \\
\hline Morley, et al., & Multicentric RCT $(N=610) ; 25-28^{+6}$ \\
2008 & weeks who were spontaneously \\
(COIN trial) & breathing in delivery room with \\
& mild to moderate respiratory \\
& distress.
\end{tabular}

Comparison
Delivery room CPAP (DR CPAP)
vs Conventional approach*

Results

a) No difference in composite outcome of BPD or death at 36 weeks of post conceptional age (PCA) [OR 0.80 (95\% CI 0.581.12)]

b) DR CPAP group spent less time on mechanical ventilation (MV), surfactant need was almost half and required less postnatal steroids for BPD $(P<0.05)$

c) Incidence of pneumothorax was high in DR CPAP group (9.1\% vs 3.0\%) compared to conventional group $(P<0.05)$

Finer, et al., 2010 Multicentric RCT

(SUPPORT trial) (randomized before delivery) $N=1316 ; 24-27^{+6}$ weeks All neonates independent of respiratory status

Dunn, et al., 2011 (VON DRM trial)

Multicentric RCT(randomized before delivery) $N=648$; 26-29+6 weeks. All neonates independent of respiratory status
Prophylactic CPAPvs

Conventional approach*

Prophylactic CPAP (nCPAP) vs Prophylactic surfactant followed by mechanical ventilation (prophylactic surfactant [PS]) = conventional approach*) vs Prophylactic surfactant with rapid extubation to CPAP (intubatesurfactant-extubate [ISX]) a) No difference in the composite outcome of BPD or death at 36 weeks of PCA [OR 0.95 (95\% CI 0.85-1.05)]

b) Need of surfactant, intubation and $\mathrm{MV}$, duration of $\mathrm{MV}$ and use of postnatal steroid for BPD was less in Prophylactic CPAP group compared to conventional group $(\mathrm{p}<0.05)$

c) No statistically significant difference in air leaks

a) No difference in composite outcome of BPD or death in PS group at 36 weeks of post conceptional age compared to nCPAP group [OR 0.83 (95\% CI 0.64-1.09)] or ISX group [OR 0.78 (95\% CI 0.591.03)]

b) In nCPAP group $48 \%$ were managed without intubation and ventilation, and 54\% without surfactant treatment

*Conventional approach: Intubation, prophylactic surfactant followed by mechanical ventilation. 
surfactant, extubation), of administering surfactant to symptomatic preterm neonates who were stabilized on CPAP. Meta-analysis of six trials comparing early surfactant administration with brief mechanical ventilation ( 1 hour) followed by extubation vs later selective surfactant and continued mechanical ventilation in neonates with RDS reported that earlier strategy is associated with a significant reduction in need of mechanical ventilation (RR 0.67, 95\% CI 0.570.79 ) and BPD (RR 0.51, 95\% CI 0.26-0.99), but the relative contribution of early surfactant in decreasing the incidence of BPD remains speculative [9].

Verder, et al. [10] and Reininger, et al. [11] showed that CPAP along with surfactant (by InSurE) as compared to CPAP alone in symptomatic preterm neonates with RD decreases the need of mechanical ventilation. The CURPAP trial [12] and the VON DRM trial [7] reported that prophylactic surfactant was not superior to nasal CPAP and early rescue surfactant in decreasing the need for mechanical ventilation in the first few days of life. Moreover, there was no difference in death or BPD at 36 weeks' postmenstrual age. A recent Cochrane systematic review (that included the SUPPORT and VON DRM trials) of prophylactic vs selective use of surfactant concluded that the benefits of prophylactic surfactant in terms of decreased air leaks and decrease mortality no longer holds true in contrast to the results of previous meta-analysis, which included studies when prophylactic or DR CPAP application was not practiced and the rate of coverage of antenatal steroids was low [13]. Moreover, a meta-analysis of these two studies alone demonstrated a compelling trend toward an increase in the risk of neonatal mortality or BPD associated with the use prophylactic surfactant when compared with early stabilization on CPAP with selective use of surfactant (typical RR 1.12, 95\% CI 1.02, 1.24] [13]. The same has been highlighted in the recent recommendations from American Academy of Pediatrics regarding the use of prophylactic surfactant in neonates $<30$ weeks gestation. There was a trend towards increased risk of BPD (RR 1.13, 95\% CI 1.00-1.28) and death or BPD (RR 1.13; $95 \%$ CI 1.02-1.25) with use of prophylactic surfactant in infants born at $<30$ weeks gestation as compared to infants who were routinely applied CPAP in the delivery room [14].

Two trials studied the ideal timing of rescue surfactant administration in moderately preterm infants (27 to 33 weeks of gestation) supported with CPAP within the first 1-2 hours of life. In both these trials for infants with RDS on CPAP, early addition of surfactant in comparison to CPAP alone was associated with lesser need for subsequent mechanical ventilation (Table II) $[15,16]$.

Overall, the current evidence supports CPAP as an acceptable safer alternative to endotracheal intubation in

TABLE II STUDIES COMPARING EARLY RESCUE SURFACTANT By INSURE AND CPAP With CPAP AlONE

\begin{tabular}{|c|c|c|c|}
\hline Author & Study design and population & Comparison & Results \\
\hline $\begin{array}{l}\text { Rojas, } \\
\text { et al., } 2009\end{array}$ & $\begin{array}{l}\text { Multicentric RCT }(\mathrm{N}=279) ; 27-31^{+6} \\
\text { weeks who were spontaneously } \\
\text { breathing in delivery room with } \\
\text { evidence of respiratory distress and } \\
\text { were on supplemental oxygen within } \\
\text { first hour of life (15 min to } 60 \mathrm{~min})\end{array}$ & $\begin{array}{l}\text { Very early rescue surfactant by } \\
\text { InSurE* followed by CPAP vs } \\
\text { CPAP alone }\end{array}$ & $\begin{array}{l}\text { a) Need for mechanical } \\
\text { ventilation was significantly } \\
\text { less in early rescue surfactant } \\
\text { group (26\% vs. 39\%); [RR } 0.69 \\
\text { ( } 95 \% \text { CI 0.49-0.97)] } \\
\text { b) Incidence of pneumothorax } \\
\text { was less in early rescue } \\
\text { surfactant group (2\% vs. 9\%); } \\
\text { [RR 0.25 (0.07-0.85) } \\
\text { c) Trend toward less BPD in early } \\
\text { rescue surfactant group ( } 49 \% \\
\text { vs. 59\%) [RR 0.84 (95\% CI } \\
\text { 0.66-1.05)] }\end{array}$ \\
\hline $\begin{array}{l}\text { Kandraju, } \\
\text { et al., } 2013\end{array}$ & $\begin{array}{l}\text { RCT }(\mathrm{N}=153) ; 28-33^{+6} \text { weeks } \\
\text { All symptomatic neonates with } \\
\text { RDS within first } 2 \text { hours of life }\end{array}$ & $\begin{array}{l}\text { Early rescue surfactant by InSurE* } \\
\text { followed by CPAP vs CPAP alone } \\
\text { initially with late }\left(\mathrm{FiO}_{2}>0.50\right) \\
\text { selective surfactant }\end{array}$ & $\begin{array}{l}\text { a) Need for mechanical } \\
\text { ventilation was significantly } \\
\text { less in early rescue surfactant } \\
\text { group (16.2\% vs. } 31.6 \%) \text {; [RR } \\
0.41 \text { (95\% CI } 0.19-0.91)] \\
\text { b) No significant difference in } \\
\text { incidence of pneumothorax and } \\
\text { BPD }\end{array}$ \\
\hline
\end{tabular}

\footnotetext{
*InSurE- Intubation, surfactant, extubation.
} 
the delivery room, and to early rescue surfactant (InSurE) for preterm infants with RDS. However, it is important to note that all these recent trials (COIN, SUPPORT, VON DRM and CURPAP) have been done in extremely preterm neonates ( $<28$ weeks) where the use of antenatal steroid coverage was very high $(>90 \%)$.

\section{Post-extubation}

Atelectasis and apnea often follow extubation in preterm neonates and nasal CPAP is used in an attempt to reduce the need for re-ventilation. A meta-analysis of nine trials showed that neonates extubated to CPAP as compared to head box oxygen had less incidence of respiratory failure (apnea, respiratory acidosis and increased oxygen requirements) [17].

\section{Apnea of Prematurity}

There is widespread use of CPAP along with methylxanthines in treatment of apnea of prematurity. However, there is no RCT which used current CPAP interface to support this practice. Moreover, ethically it may not be possible to compare CPAP with 'no treatment group' to treat apnea of prematurity.

\section{Other Applications}

CPAP may be useful in other conditions that result in alveolar collapse or airway narrowing. It relieves the signs of cardiac failure due to patent ductus arteriosus. Similarly, it is often used in the management of pneumonia, transient tachypnea of newborn, postoperative respiratory management, pulmonary edema and pulmonary hemorrhage. In meconium aspiration syndromes (MAS), application of CPAP can be beneficial by resolving the atelectatic alveoli due to alveolar injury and secondary surfactant deficiency [18]. In an observational study of 66 neonates with MAS, in whom CPAP was started at a mean age of 5.3 hours, Murki, et al. [19] showed that $75 \%$ could be managed successfully with CPAP alone, especially if they were inborn. Incidence of pneumothorax in this study was $2.6 \%$ [19]. There is no head-to-head comparison of CPAP with mechanical ventilation in MAS. CPAP has been used for the management of laryngo/tracheo/bronchomalacia as positive pressure distends the large airways as well, and overcome their tendency to collapse, especially during expiration.

\section{Appropriate Pressure for CPAP}

There is paucity of data regarding the ideal range of CPAP pressures in neonates [20]. In a recent RCT, neonates ( $n=93$ ) of 23-30 week gestation with residual lung disease (needing $\mathrm{FiO}_{2}>0.25$ ) who were being

TABLE III RECENT TRIALS OF CPAP WEANING

\begin{tabular}{|c|c|c|c|}
\hline Author & Study design and population & Comparison & Results \\
\hline \multirow[t]{2}{*}{$\begin{array}{l}\text { Abdel-Hady, } \\
\text { et al., } 2011\end{array}$} & \multirow[t]{2}{*}{$\begin{array}{l}\mathrm{RCT}(N=60) ; \geq 28 \text { weeks who were } \\
\text { clinically stable on NCPAP of } 5 \\
\mathrm{cmH}_{2} \mathrm{O} \text { with } \mathrm{FiO} 2<0.30 \text { for at least } \\
24 \text { hours }\end{array}$} & $\begin{array}{l}\text { No nasal cannula (No-NC) group: } \\
\text { Infants kept on NCPAP until they } \\
\text { were on FiO2=0.21 for } 24 \mathrm{~h} \text {, and } \\
\text { then were weaned off NCPAP } \\
\text { completely without any exposure } \\
\text { to NC vs }\end{array}$ & $\begin{array}{l}\text { a) No-NC group had fewer days } \\
\text { on oxygen and shorter duration } \\
\text { of respiratory support }\end{array}$ \\
\hline & & $\begin{array}{l}\text { Nasal cannula (NC) group: } \\
\text { Infants weaned off NCPAP when } \\
\mathrm{FiO} 2 \text { was } \leq 0.30 \text { to NC }(2 \mathrm{~L} / \mathrm{min} \text { of } \\
\text { oxygen) followed by gradual } \\
\text { weaning from oxygen }\end{array}$ & $\begin{array}{l}\text { b) No difference regarding } \\
\text { success of weaning from } \\
\text { NCPAP }\end{array}$ \\
\hline $\begin{array}{l}\text { Todd, } \\
\text { et al., } 2012\end{array}$ & $\begin{array}{l}\text { Multicentric RCT }(N=177) ;<30 \text { weeks } \\
\text { who were clinically stabile on CPAP } \\
4-6 \text { cm with FiO2 }<25 \% \text { for at least } \\
12 \text { hours }\end{array}$ & $\begin{array}{l}\text { M1: Taken 'OFF' CPAP with the } \\
\text { view to stay 'OFF' vs } \\
\text { M2: Cycled on and off CPAP with } \\
\text { incremental time 'OFF' vs } \\
\text { M3: As with M2, cycled on and off } \\
\text { CPAP but during 'OFF' periods } \\
\text { were supported by nasal cannula at } \\
\text { a flow of } 0.51 / \text { min }\end{array}$ & $\begin{array}{l}\text { Method } 1 \text { significantly } \\
\text { shortened CPAP weaning time, } \\
\text { CPAP duration, oxygen } \\
\text { duration, BPD and length of } \\
\text { admission }\end{array}$ \\
\hline $\begin{array}{l}\text { O’Donnell, } \\
\text { et al., } 2013\end{array}$ & $\begin{array}{l}2 \text { center } \mathrm{RCT}(N=78) \text {; VLBW infants } \\
\text { who were stable on CPAP of } 3-5 \mathrm{~cm} \\
\mathrm{H}_{2} \mathrm{O} \text { with } \mathrm{FiO}=0.21 \text { for } 24 \text { hours }\end{array}$ & $\begin{array}{l}\text { Nasal prong group: Treated with } \\
\text { low-flow }(1.0 \mathrm{~L} / \mathrm{min}) \text { nasal prongs } \\
\text { with room air vs Spontaneous } \\
\text { breathing in room air }\end{array}$ & $\begin{array}{l}\text { No significant difference in } \\
\text { failure rate of weaning from } \\
\text { CPAP [ } 41 \% \text { in nasal prong } \\
\text { group vs } 31 \% \text { in spontaneous } \\
\text { breathing group }(P=0.48)] \text {. }\end{array}$ \\
\hline
\end{tabular}


extubated for the first time were randomized to receive low $(4-6 \mathrm{~cm})$ or high $(7-9 \mathrm{~cm})$ CPAP pressure [21]. The rates of extubation failure and re-intubation within 96 hours of extubation were significantly lower in the high CPAP pressure group. This was mainly due to strikingly lower failure rates in 500-750 g birth weight group [21].

\section{Weaning}

A questionnaire survey done in 58 units in England revealed that 36 (66\%) of the units used to wean by 'time off', 2 (4\%) by weaning pressure, and in remaining 30\%, there was no set method [22]. A randomized trial comparing the strategy of weaning pressure with one of increasing time off-CPAP showed a significant shorter duration of weaning with the 'pressure' strategy (1.5 days in pressure group $v s 9$ days in 'time off'; $P$ 0.001) [23]. A Cochrane review of three RCTs concluded that neonates in whom CPAP pressure was weaned to a predefined level, and then CPAP was stopped completely have less total time on CPAP and shorter durations of oxygen therapy and hospital stay compared with those in whom CPAP was removed for a pre-determined number of hours each day [24]. The overall evidence (Table III) [25-27] favors abrupt stoppage of CPAP after achieving the stability criteria without any exposure to nasal cannula. The point at which to attempt abrupt stoppage of CPAP needs to be established in future trials.

\section{IDEAL CPAP DEVICE}

\section{CPAP Pressure Generator (Table IV) [28-33]}

Bubble CPAP has the advantage over ventilator CPAP in producing pressure oscillations superimposed over the pressure fluctuations, as a result of spontaneous breathing. The noisy pressure waveform superimposed over pressure fluctuations (stochastic resonance effect) promotes lung recruitment resulting in better oxygenation [29]. Moreover, additional benefits accrue with bubble CPAP due to higher delivered pressure as compared to set pressure because of its flow-dependent nature. In spite of theoretical advantage of variable flow CPAP devices, data supporting its clinical superiority across all the settings are scarce (Web Table I) [34-48]. In a recent RCT comparing Benveniste valve (Jet CPAP) with bubble CPAP in neonates with RDS, there was no difference in the failure rate, mortality or any other morbidity between the two groups. The prong displacements were more common with Benveniste valve (Jet CPAP) as compared to bubble CPAP. However, the pain scores in neonates were lesser with Benveniste valve [49].

Though, there is some evidence for the superiority of IFD and bubble CPAP over ventilator CPAP but the differences in study design, indications, short study

TABLE IV: STUdies COMPARING BUBBLE CPAP AND VENTILATOR CPAP

\begin{tabular}{lll}
\hline Author & Study design and population & Results \\
\hline Lee, et al., 1998 & Randomized crossover design & 39\% reduction in infant's lung volume and 7\% \\
& $N=10 ; 750-2,000 \mathrm{~g}$, & $\begin{array}{l}\text { reduction in respiratory rate but no difference in blood } \\
\text { gas parameters in infants on bubble CPAP }\end{array}$ \\
& preterm neonates ready for extubation & Bubble CPAP associated with a higher $\mathrm{pH}, \mathrm{PaO} 2$, \\
Pillow, et al., 2007 & $\begin{array}{l}\text { Experimental (lamb model) } \\
N=34 ; \text { Preterm lambs treated with CPAP for 3 hours }\end{array}$ & $\begin{array}{l}\text { oxygen uptake, and a decreased alveolar protein \& } \\
\text { ventilation in-homogeneity }\end{array}$
\end{tabular}

Tagare, et al., $2010 \quad$ RCT (pilot study) $N=30$; Preterm ( $<37$ weeks) neonates with respiratory distress and oxygen requirement $>30 \%$ in first 6 hour of life

Courtney, et al., 2011 Randomized with crossover design $N=18$; Neonates $<1500$ g and $<28$ days old and on NCPAP for mild respiratory distress

Success rate and dislodgement rate were comparable

No significant difference in work of breathing, tidal volume, respiratory rate, heart rate, breathing asynchrony but transcutaneous oxygen was higher with Bubble CPAP

Yadav, et al., 2012 RCT (pilot study)

$N=32$; Neonates $\geq 32$ weeks and $<1500 \mathrm{~g}$

Bubble CPAP associated with 50\% reduction in the extubation failure rate though difference was not statistically significant

Tagare, et al., $2013 \quad$ RCT

$N=114$; preterm neonates with SilvermanBubble CPAP has higher success rate than ventilator CPAP (82.5\% vs 63.2\%)

Anderson score ? 4 and oxygen requirement $>30 \%$ within first 6 hours of life 
epochs and insufficient relevant clinical outcomes necessitate the need for further studies on this issue.

\section{Heated Humidified High-flow Nasal Cannula (HHFNC)}

Simple nasal cannulas with an outer diameter of $3 \mathrm{~mm}$ and flows up to $2 \mathrm{~L} / \mathrm{min}$, have been reported to deliver CPAP. In humidified high-flow nasal cannula (HHFNC), warm and humidified respiratory gases are delivered at flow rates between 2 to $8 \mathrm{~L} / \mathrm{min}$. A systematic review of 19 studies concluded that HHHFNC may be as effective as nasal NCPAP in improving respiratory parameters, but its efficacy and safety in preterm neonates need further research [50]. A recent multicentric RCT in 432 neonate (28 to 42 weeks) comparing HHHFNC with CPAP device for planned nasal CPAP support, as either primary therapy or in post-extubation setting did not find any difference in early failure $(10.8 \%$ vs $8.2 \%)$ or subsequent need for any intubation $(15.1 \%$ vs $11.4 \%)$. HHHFNC neonates remained on the study mode significantly longer than nasal CPAP neonates (median: 4 vs 2 days, $P<0.01$ ), but there were no differences for days on supplemental oxygen, and BPD [51]. Another RCT on 132 neonates ( $<32$ weeks gestation) in postextubation setting did not find any difference in extubation failure rate (22\% in HHHFNC vs $34 \%$ in NCPAP) within seven days after extubation. However, the nasal trauma score was significantly less in HHHFNC group ( 3.1 vs $11.8 ; P<0.001$ ) as compared to NCPAP group [52]. A randomized crossover trial found similar patient comfort score in preterm infants $(n=20$, $<34$ weeks gestation) who were treated with HHHFNC or NCPAP due to mild respiratory illness. However, parents preferred HHHFNC because of better child satisfaction, interaction and possibility to take part in care [53]. In a recent multicentric non-inferiority RCT done among neonates $<32$ weeks gestation $(n=303)$ in post-extubation setting, the use of HHHFNC was not inferior to NCPAP. The treatment failure within seven days after extubation occurred in $34.2 \%$ in HHHFNC group as compared to $25.8 \%$ in NCPAP group [54]. However, like previous trials, neonates in HHHFNC group had a significantly lower incidence of nasal trauma than those in the NCPAP group (39.5\% vs $54.3 \%, P=$ $0.01)$. Thus, HHHFNC may have a potential role as an alternative to CPAP in post- extubation setting due to its ease of application and less nasal trauma.

\section{Patient Interface}

The most common interfaces used for CPAP are nasal prongs and nasal masks. Nasal prongs can be short (6-15 $\mathrm{mm}$ ) or long (40-90 mm), and single or binasal. The long nasal prong which is actually a nasopharyngeal prong has the disadvantages of a high resistance, more prone to kinking and blockage by secretions, and difficulty in monitoring local side effects. The short binasal prongs include Argyle, Hudson, Medicorp, F and P, prongs and IFD prongs. Short binasal prongs have the least resistance to flow and are more effective at preventing re-intubation than single nasal or nasopharyngeal prongs [RR 0.59; 95\% CI: 0.41, 0.85] in preterm neonates [55]. In patients with RDS, short binasal prongs were found to be superior to nasopharyngeal prongs in terms of lower oxygen requirement and less respiratory rate in first 48 hours [56]. Information about short binasal prongs is limited. A study comparing Hudson with Argyl prongs in preterm neonates, receiving nasal CPAP as initial ventilatory assistance or for weaning from a ventilator, concluded that Argyle prong is more difficult to be retained in the nostrils of active patients and nasal hyperemia occurs more frequently with its use [57].

In another RCT among VLBW neonates, comparing nasal prongs with nasal mask, no significant difference was noted in the incidence of nasal injury [58]. A randomized trial in neonates $<31$ weeks gestation comparing nasal mask with binasal prongs showed less intubation rate within 72 hours for the treatment of RDS or in post-extubation setting with nasal mask (28\% vs 52\%; $P=0.007$ ) [59]. In a recent RCT from India, Chandrasekaran, et al. [60] reported a 6\% reduction in the oxygen requirement at 2 hours of CPAP initiation with nasal mask as compared to nasal prongs. Moreover, infants on nasal mask had no nasal injury (31.3\% vs $0 \%$; $P<0.01)$. On post-hoc analysis, the need for surfactant after starting CPAP was markedly lesser (95\% CI 33\% $89 \%, P<0.01$ ) [60]. More evidence is required before nasal masks can replace short binasal prongs.

'RAM cannula' is a binasal prong like the oxygen prongs but with a diameter much wider than the conventional oxygen prongs. It is easy to apply and retains the benefit of a circuit with inspiratory and expiratory limbs to provide non-invasive ventilation. Preliminary data is promising but more evidence is required to support its use [61]. Nzegwu, et al. [62], in a recent prospective observational study showed that RAM cannula was well tolerated in neonates. The overall success rate in weaning off the RAM cannula was $66 \%$ in newborns who were on CPAP with FiO2 $\leq 0.35$ [62].

\section{Recent Advances}

Bilevel nasal CPAP, popularly known as BiPAP/SiPAP is a newer mode of non-invasive respiratory support similar to CPAP where two levels of CPAP $\left(\mathrm{P}_{\text {high }}\right.$ and $\left.\mathrm{P}_{\text {low }}\right)$ are given at preset time intervals $\left(\mathrm{T}_{\text {high }}\right.$ [time the CPAP pressures are high] and $\mathrm{T}_{\text {low }}$ [time the CPAP 
pressures are low]). A study evaluating BiPAP after InSurE failure to prevent the need for mechanical ventilation among VLBW neonates $(n=60)$ found that the need of mechanical ventilation was $27 \%$ in the historical controls as compared to $0 \%$ in the BiPAP group [63]. A RCT by Lista, et al. [64] comparing BIPAP with CPAP among neonates with RDS between 28-34 weeks of gestation $(n=40)$ found similar cytokine levels in serum on day 1 and 7 of life. However, neonates in CPAP group required longer respiratory support and oxygen therapy, and were discharged later [64]. Another RCT comparing CPAP with BiPAP in the postextubation setting among neonates $(n=136)$ with birth weight $\leq 1250 \mathrm{~g}$ did not find any difference in the incidence of sustained extubation for next 7 days after extubation [65]. Thus, preliminary data is encouraging but more evidence is required in this direction.

Another recent innovation is Sea-PAP, a modification of bubble CPAP, where a segment of the expiratory tube immersed in water has been bent at an angle of $135^{\circ}$ [66]. The rationale is to increase the amplitude of the oscillations which are superimposed on the pressure fluctuations, which may result in better recruitment of alveoli and better gas exchange. Preliminary data in animal studies are promising but the device requires clinical evaluation [67].

\section{LONG Term Outcomes of CPAP}

In a retrospective analysis, Thomas, et al. [68] compared the ventilator support strategy (CPAP vs. mechanical ventilation) at $24 \mathrm{~h}$ of age to predict neurodevelopmental outcomes. After adjusting for illness severity, those on CPAP at 24 hours of life had better Bayley Scores of Infant Development at 18-22 months of corrected age apart from lower BPD and lower mortality [68]. In the SUPPORT trial, there was no statistically significant difference in the composite outcome of death or neurodevelopmental impairment at 18-22 months of corrected age in early CPAP group as compared to mechanical ventilation and surfactant group [69]. Further studies are required to evaluate long-term impact of CPAP on various development and respiratory outcomes.

\section{IMPLICATIONS AND APPLICABILITY}

Assuming the incidence of RDS to be $1.2 \%$ among livebirths, nearly 1,86,000 infants each year are affected with RDS in India [70]. With a reported mortality of 57\% to $89 \%$ among infants with RDS, nearly 100,000 infants each year are estimated to die due to RDS [71]. Mechanical ventilation and CPAP are the mainstay in the management of RDS. Even the low-cost indigenously designed CPAP systems have been shown to be effective in reducing the mortality and up-transfers among term and preterm neonates with respiratory distress in lowand middle-income countries [72-74].

A recent systematic review [75] examining the efficacy and safety of bubble CPAP in neonates with respiratory distress in low- and middle-income countries found that the initial use of bubble CPAP compared with oxygen therapy reduced the need for mechanical ventilation by $30-50 \%$. Although the mortality and the complication rates between the bubble CPAP and ventilator CPAP were similar, the CPAP failure rate was lower in the bubble CPAP group as compared to ventilator CPAP (3 RCTs, OR 0.32, 95\% CI 0.16, 0.67; $P<0.003)$. Better outcomes were seen in neonates with birth weight $>1000 \mathrm{~g}$ than neonates $<1000 \mathrm{~g}$, and in those with mild to moderate respiratory distress compared to neonates with more severe disease. Moreover, bubble CPAP can be effectively and safely applied by nurses and other health workers after their initial training in these settings, and thus may improve neonatal survival and quality of neonatal care [75].

Most places except few referral neonatal units, teaching hospitals and medical colleges cannot provide invasive ventilation in developing countries. Therefore, CPAP appears to be the best option to manage infant with RDS and to prevent up-transfers to already over-burdened Level III/tertiary care centers. It also reduces cost of care by reducing the need for mechanical ventilation and surfactant [76]. Early use of CPAP will be a simple and cost effective intervention in resource-limited settings.

With the substantial increase in the CPAP use over last decade, future seems promising. However, dependence on imported CPAP devices, lack of an ideal interface, non-availability of round-the-clock air/oxygen supply, surfactant and backup ventilation, lack of awareness and expertise among doctors and inadequately trained nursing staff are the major challenges. This situation is further compounded by overcrowded delivery rooms and lack of NICU beds. Good antenatal care, timely referral, and optimum delivery and newborn care practices should be equally addressed to get maximum benefits from CPAP.

Our initial focus should be primarily on infants with gestation $>28$ weeks to make a larger impact. However, as survival of extremely low birth weight neonates has improved, tertiary care centers should focus on very early CPAP in the delivery room. The concerns of associated morbidities and long-term sequelae should be addressed with simultaneous improvements in effective resuscitation, asepsis, breast milk feeding, aggressive nutrition, intensive monitoring, and screening for complications. 
CPAP is a big boon for resource-limited countries, provided it is started early and used judiciously along with holistic care and proper follow-up services.

Contribution: All authors contributed to review of literature, manuscript drafting and its final approval.

Funding: None; Competing interests: None stated.

\section{REFERENCES}

1. Ho JJ, Subramaniam P, Henderson-Smart DJ, Davis PG. Continuous distending pressure for respiratory distress syndrome in preterm infants. Cochrane Database Syst Rev. 2002;2:CD002271.

2. Buckmaster AG, Arnolda GR, Wright IM, HendersonSmart DJ. CPAP use in babies with respiratory distress in Australian special care nurseries. J Paediatr Child Health. 2007;43:376-82.

3. Kiran S, Murki S, Pratap OT, Kandraju H, Reddy A. Nasal continuous positive airway pressure therapy in a nontertiary neonatal unit: Reduced need for up-transfers. Indian J Pediatr. 2014 Jun 21. [Epub ahead of print].

4. Ho JJ, Henderson-Smart DJ, Davis PG. Early versus delayed initiation of continuous distending pressure for respiratory distress syndrome in preterm infants. Cochrane Database Syst Rev. 2002;2:CD002975.

5. Morley CJ, Davis PG, Doyle LW, Brion LP, Hascoet JM, Carlin JB; COIN Trial Investigators. Nasal CPAP or intubation at birth for very preterm infants. N Engl J Med. 2008;358:700-8.

6. SUPPORT Study Group of the Eunice Kennedy Shriver NICHD Neonatal Research Network, Finer NN, Carlo WA, Walsh MC, Rich W, Gantz MG, Laptook AR, et al. Early CPAP versus surfactant in extremely preterm infants. N Engl J Med. 2010;362:1970-9.

7. Dunn MS, Kaempf J, de Klerk A, de Klerk R, Reilly M, Howard D; Vermont Oxford Network DRM Study Group. Randomized trial comparing 3 approaches to the initial respiratory management of preterm neonates. Pediatrics. 2011;128:1069-76.

8. Verder H, Agertoft L, Albertsen P, Christensen NC, Curstedt T, Ebbesen F, et al. Surfactant treatment of newborn infants with respiratory distress syndrome primarily treated with nasal continuous positive air pressure. A pilot study. Ugeskr Laeger. 1992;154:2136-9.

9. Stevens TP, Harrington EW, Blennow M, Soll RF. Early surfactant administration with brief ventilation $v$ s selective surfactant and continued mechanical ventilation for preterm infants with or at risk for respiratory distress syndrome. Cochrane Database Syst Rev. 2007;4:CD003063.

10. Verder H, Robertson B, Greisen G, Ebbesen F, Albertsen $\mathrm{P}$, Lundstrom $\mathrm{K}$, et al. Surfactant therapy and nasal continuous positive airway pressure for newborns with respiratory distress syndrome. Danish-Swedish Multicenter Study Group. N Engl J Med. 1994;331: 1051-5.

11. Reininger A, Khalak R, Kendig JW, Ryan RM, Stevens TP, Reubens L, et al. Surfactant administration by transient intubation in infants 29 to 35 weeks' gestation with respiratory distress syndrome decreases the likelihood of later mechanical ventilation: A randomized controlled trial. J Perinatol. 2005;25:703-8.

12. Sandri F, Plavka R, Ancora G, Simeoni U, Stranak Z, Martinelli S, et al; CURPAP Study Group. Prophylactic or early selective surfactant combined with nCPAP in very preterm infants. Pediatrics. 2010;125:1402-9.

13. Rojas-Reyes MX, Morley CJ, Soll R. Prophylactic versus selective use of surfactant in preventing morbidity and mortality in preterm infants. Cochrane Database Syst Rev. 2012;3:CD000510.

14. Polin RA, Carlo WA; Committee on Fetus and Newborn; American Academy of Pediatrics. Surfactant replacement therapy for preterm and term neonates with respiratory distress. Pediatrics. 2014;133:156-63.

15. Rojas MA, Lozano JM, Rojas MX, Laughon M, Bose CL, Rondon MA, et al; Colombian Neonatal Research Network. Very early surfactant without mandatory ventilation in premature infants treated with early continuous positive airway pressure: a randomized, controlled trial. Pediatrics. 2009;123:137-42.

16. Kandraju H, Murki S, Subramanian S, Gaddam P, Deorari A, Kumar P. Early routine versus late selective surfactant in preterm neonates with respiratory distress syndrome on nasal continuous positive airway pressure: A randomized controlled trial. Neonatology. 2013;103:148-54.

17. Davis PG, Henderson-Smart DJ. Nasal continuous positive airways pressure immediately after extubation for preventing morbidity in preterm infants. Cochrane Database Syst Rev. 2003;2:CD000143.

18. Goldsmith JP. Continuous positive airway pressure and conventional mechanical ventilation in the treatment of meconium aspiration syndrome. J Perinatol. 2008;28: S49-55.

19. Priya B, Murki S. CPAP for Meconium Aspiration Syndrome: Predictors of Failure. In: Thakre R, Pejaver RK. editors. Proceedings of VI Annual Convention of Neonatology Chapter of Indian Academy of Pediatrics: IAP Neocon 2013 Abstracts. Ahmedabad, India: IAP Neonatal Chapter India; 2013. p.12.

20. Davis PG, Morley CJ. Non-invasive respiratory support: An alternative to mechanical ventilation in preterm infants. In: Bancalari E (ed). The Newborn Lung. Neonatology questions and new controversies. 1st edn. Philadelphia: Saunders 2008: p. 361-76.

21. Buzzella B, Claure N, D’Ugard C, Bancalari E. A randomized controlled trial of two nasal continuous positive airway pressure levels after extubation in preterm infants. J Pediatr. 2014;164:46-51.

22. Bowe L, Clarke P. Current use of nasal continuous positive airways pressure in neonates. Arch Dis Child Fetal Neonatal Ed. 2005;90:F92-3.

23. Singh SD, Robinson MJ, Clarke P, Bowe L, Smith J, Glover K, et al. Nasal CPAP weaning of VLBW infants: Is decreasing CPAP pressure or increasing time off the better strategy? Results of a randomized controlled trial. Early Hum Dev. 2007;83:125-37.

24. Jardine LA, Inglis GD, Davies MW. Strategies for the withdrawal of nasal continuous positive airway pressure 
(NCPAP) in preterm infants. Cochrane Database Syst Rev. 2011;2:CD006979.

25. Abdel-Hady H, Shouman B, Aly H. Early weaning from CPAP to high flow nasal cannula in preterm infants is associated with prolonged oxygen requirement: A randomized controlled trial. Early Hum Dev. 2011;87: 205-8.

26. Todd DA, Wright A, Broom M, Chauhan M, Meskell S, Cameron $\mathrm{C}$ et al. Methods of weaning preterm babies $<30$ weeks gestation off CPAP: A multicentre randomised controlled trial. Arch Dis Child Fetal Neonatal Ed. 2012;97:F236-40.

27. O’Donnell SM, Curry SJ, Buggy NA, Moynihan MM, Sebkova S, Janota J, et al. The NOFLO trial: Low-flow nasal prongs therapy in weaning nasal continuous positive airway pressure in preterm infants. J Pediatr. 2013;163: 79-83.

28. Lee KS, Dunn MS, Fenwick M, Shennan AT. A comparison of underwater bubble continuous positive airway pressure with ventilator-derived continuous positive airway pressure in premature neonates ready for extubation. Biol Neonate. 1998;73:69-75.

29. Pillow JJ, Hillman N, Moss TJ, Polglase G, Bold G, Beaumont $\mathrm{C}$, et al. Bubble continuous positive airway pressure enhances lung volume and gas exchange in preterm lambs. Am J Respir Crit Care Med. 2007;176: 63-9.

30. Tagare A, Kadam S, Vaidya U, Pandit A, Patole S. A pilot study of comparison of BCPAP vs VCPAP in preterm infants with early onset respiratory distress. J Trop Pediatr. 2010;56:191-4.

31. Courtney SE, Pyon KH, Saslow JG, Arnold GK, Pandit PB, Habib RH. Lung recruitment and breathing pattern during variable versus continuous flow nasal continuous positive airway pressure in premature infants: an evaluation of three devices. Pediatrics. 2001;107:304-8.

32. Yadav S, Thukral A, Sankar MJ, Sreenivas V, Deorari AK, Paul VK, et al. Bubble vs conventional continuous positive airway pressure for prevention of extubation failure in preterm very low birth weight infants: A pilot study. Indian J Pediatr. 2012;79:1163-68.

33. Tagare A, Kadam S, Vaidya U, Pandit A, Patole S. Bubble CPAP versus ventilator CPAP in preterm neonates with early onset respiratory distress-A randomized controlled trial. J Trop Pediatr. 2013;59:113-9.

34. Moa G, Nilsson K, Zetterström H, Jonsson LO. A new device for administration of nasal continuous positive airway pressure in the newborn: an experimental study. Crit Care Med. 1988;16:1238-42.

35. Klausner JF, Lee AY, Hutchison AA. Decreased imposed work with a new nasal continuous positive airway pressure device. Pediatr Pulmonol. 1996;22:188-94.

36. Ahluwalia JS, White DK, Morley CJ. Infant flow driver or single prong nasal continuous positive airway pressure: short-term physiological effects. Acta Paediatr. 1998;87:325-7.

37. Courtney SE, Pyon KH, Saslow JG, Arnold GK, Pandit PB, Habib RH. Lung recruitment and breathing pattern during variable versus continuous flow nasal continuous positive airway pressure in premature infants: an evaluation of three devices. Pediatrics. 2001;107:304-8.

38. Pandit PB, Courtney SE, Pyon KH, Saslow JG, Habib RH. Work of breathing during constant- and variable-flow nasal continuous positive airway pressure in preterm neonates.Pediatrics. 2001;108:682-5.

39. Mazzella M, Bellini C, Calevo MG, Campone F, Massocco $\mathrm{D}$, Mezzano $\mathrm{P}$, et al. A randomised control study comparing the Infant Flow Driver with nasal continuous positive airway pressure in preterm infants. Arch Dis Child Fetal Neonatal Ed. 2001;85:F86-90.

40. Liptsen E, Aghai ZH, Pyon KH, Saslow JG, Nakhla T, Long $\mathrm{J}$, et al. Work of breathing during nasal continuous positive airway pressure in preterm infants: a comparison of bubble vs variable-flow devices. J Perinatol. 2005;25:453-8.

41. Boumecid H, Rakza T, Abazine A, Klosowski S, Matran R, Storme L. Influence of three nasal continuous positive airway pressure devices on breathing pattern in preterm infants. Arch Dis Child Fetal Neonatal Ed. 2007;92: F298-300.

42. Pantalitschka T, Sievers J, Urschitz MS, Herberts T, Reher C, Poets CF. Randomised crossover trial of four nasal respiratory support systems for apnoea of prematurity in very low birthweight infants. Arch Dis Child Fetal Neonatal Ed. 2009;94:F245-8.

43. Yagui AC, Vale LA, Haddad LB, Prado C, Rossi FS, Deutsch $\mathrm{AD}$, et al. Bubble CPAP versus CPAP with variable flow in newborns with respiratory distress: a randomized controlled trial. J Pediatr (Rio J). 2011;87: 499-504.

44. Bober K, EEwietliñski J, Zejda J, Kornacka K, Pawlik D, Behrendt J, et al. A multicenter randomized controlled trial comparing effectiveness of two nasal continuous positive airway pressure devices in very-low-birth-weight infants. Pediatr Crit Care Med. 2012;13:191-6.

45. Kirchner L, Wald M, Jeitler V, Pollak A. In vitro comparison of noise levels produced by different CPAP generators. Neonatology. 2012;10:95-100.

46. Huckstadt T, Foitzik B, Wauer RR, Schmalisch G. Comparison of two different CPAP systems by tidal breathing parameters. Intensive Care Med. 2003;29: 1134-40.

47. Stefanescu BM, Murphy WP, Hansell BJ, Fuloria M, Morgan TM, Aschner JL. A randomized, controlled trial comparing two different continuous positive airway pressure systems for the successful extubation of extremely low birth weight infants. Pediatrics. 2003;112;1031-8.

48. Gupta S, Sinha SK, Tin W, Donn SM. A randomized controlled trial of post-extubation bubble continuous positive airway pressure versus infant flow driver continuous positive airway pressure in preterm infants with respiratory distress syndrome. J Pediatr. 2009;154:645-50.

49. Bhatti A, Khan J, Murki S, Sundaram V, Saini SS, Kumar P. Jet Continuous positive airway pressure versus bubble continuous positive airway pressure in preterm babies with respiratory distress: A randomized controlled trial. E-PAS. 2014:4680.5

50. Manley BJ, Dold SK, Davis PG, Roehr CC. High-flow 
nasal cannulae for respiratory support of preterm infants: a review of the evidence. Neonatology. 2012;102:300-8.

51. Yoder BA, Stoddard RA, Li M, King J, Dirnberger DR, Abbasi S. Heated, humidified high-flow nasal cannula versus nasal cpap for respiratory support in neonates. Pediatrics. 2013;131:e1482-90.

52. Collins CL, Holberton JR, Barfield C, Davis PG. A randomized controlled trial to compare heated humidified high-flow nasal cannulae with nasal continuous positive airway pressure postextubation in premature infants. $\mathrm{J}$ Pediatr. 2013;162:949-54.

53. Klingenberg C, Pettersen M, Hansen EA, Gustavsen LJ, Dahl IA, Leknessund A, et al. Patient comfort during treatment with heated humidified high flow nasal cannulae versus nasal continuous positive airway pressure: A randomised cross-over trial. Arch Dis Child Fetal Neonatal Ed. 2014;99:F134-7.

54. Manley BJ, Owen LS, Doyle LW, Andersen CC, Cartwright DW, Pritchard MA, et al. High-flow nasal cannulae in very preterm infants after extubation. $\mathrm{N}$ Engl $\mathrm{J}$ Med. 2013;369:1425-33.

55. De Paoli AG, Davis PG, Faber B, Morley CJ. Devices and pressure sources for administration of nasal continuous positive airway pressure (NCPAP) in preterm neonates. Cochrane Database Syst Rev. 2008;1:CD002977.

56. Mazzella M, Bellini C, Calevo MG, Campone F, Massocco $\mathrm{D}$, Mezzano $\mathrm{P}$, et al. A randomised control study comparing the Infant Flow Driver with nasal continuous positive airway pressure in preterm infants. Arch Dis Child Fetal Neonatal Ed. 2001;85:F86-90.

57. Rego MA, Martinez FE. Comparison of two nasal prongs for application of continuous positive airway pressure in neonates. Pediatr Crit Care Med. 2002;3:239-43.

58. Yong SC, Chen SJ, Boo NY. Incidence of nasal trauma associated with nasal prong versus nasal mask during continuous positive airway pressure treatment in very low birthweight infants: A randomised control study, Arch Dis Child Fetal Neonatal Ed. 2005;90:F480-83.

59. Kieran EA, Twomey AR, Molloy EJ, Murphy JF, O’Donnell CP. Randomized trial of prongs or mask for nasal continuous positive airway pressure in preterm infants. Pediatrics. 2012;130:1170-6.

60. Chandrasekaran A, Sachdeva A, Sankar MJ, Agarwal R, Deorari AK, Paul VK. Nasal mask versus nasal prongs in the delivery of continuous positive airway pressure in preterm infants - An open label randomized controlled trial. E-PAS. 2014:2936.512.

61. Horton D, Durand D. Use of a new nasal cannula to deliver nasal ventilation to NICU patients. Open forum abstracts; Journal of respiratory care 2012.

62. Nzegwu NI, Mack T, DellaVentura R, Dunphy L, Koval N, Levit O, et al. Systematic use of the RAM nasal cannula in the Yale-New Haven Children's Hospital Neonatal Intensive Care Unit: A quality improvement project. J Matern Fetal Neonatal Med. 2014 Jun 30:1-4. [Epub ahead of print].

63. Ancora G, Maranella E, Grandi S, Pierantoni L, Guglielmi
M, Faldella G. Role of bilevel positive airway pressure in the management of preterm newborns who have received surfactant.Acta Paediatr. 2010;99:1807-11.

64. Lista G, Castoldi F, Fontana P, Daniele I, Cavigioli F, Rossi $\mathrm{S}$, et al. Nasal continuous positive airway pressure (CPAP) versus bi-level nasal CPAP in preterm babies with respiratory distress syndrome: A randomised control trial. Arch Dis Child Fetal Neonatal Ed. 2010;95:F85-9.

65. O’Brien K, Campbell C, Brown L, Wenger L, Shah V. Infant flow biphasic nasal continuous positive airway pressure (BP- NCPAP) vs infant flow NCPAP for the facilitation of extubation in infants' $<1,250$ grams: A randomized controlled trial. BMC Pediatr. 2012;12:43-51.

66. Sea-PAP. A Lifesaving Innovation for Infant Respiratory Distress. Available from: http://www.seattlechildrens.org/ research/developmental-therapeutics/labsprograms/ neonatal-respiratory-support-technologies-team/seaPAP/ Accessed June 25, 2014.

67. Diblasi RM, Zignego JC, Smith CV, Hansen TN, Richardson CP. Effective gas exchange in paralyzed juvenile rabbits using simple, inexpensive respiratory support devices. Pediatr Res. 2010;68:526-30.

68. Thomas CW, Meinzen-Derr J, Hoath SB, Narendran V. Neurodevelopmental outcomes of extremely low birth weight infants ventilated with continuous positive airway pressure vs mechanical ventilation. Indian J Pediatr. 2012;79:218-23.

69. Vaucher YE, Peralta-Carcelen M, Finer NN, Carlo WA, Gantz MG, Walsh MC; SUPPORT Study Group of the Eunice Kennedy Shriver NICHD Neonatal Research Network. Neurodevelopmental outcomes in the early CPAP and pulse oximetry trial. $\mathrm{N}$ Engl $\mathrm{J}$ Med. 2012;367:2495-504.

70. Report of the National Neonatal Perinatal Database. NNF India, 2002-2003.

71. Kumar A, Bhat BV. Epidemiology of respiratory distress of newborns. Indian J Pediatr. 1996;63:93-8.

72. Daga S, Mhatre S, Borhade A, Khan D. Home-made continuous positive airways pressure device may reduce mortality in neonates with respiratory distress in lowresource setting. J Trop Pediatr. 2014;60:343-7.

73. Hendriks H, Kirsten GF, Voss M, Conradie H. Is continuous positive airway pressure a feasible treatment modality for neonates with respiratory distress syndrome in a rural district hospital? J Trop Pediatr. 2014;60:348-51.

74. Kawaza K, Machen HE, Brown J, Mwanza Z, Iniguez S, Gest A, et al. Efficacy of a low-cost bubble CPAP system in treatment of respiratory distress in a neonatal ward in Malawi. PLoS One. 2014;9:e86327.

75. Martin S, Duke T, Davis P. Efficacy and safety of bubble CPAP in neonatal care in low and middle income countries: a systematic review. Arch Dis Child Fetal Neonatal Ed. 2014;99:F495-504.

76. Kamath BD, Macguire ER, McClure EM, Goldenberg RL, Jobe AH. Neonatal mortality from respiratory distress syndrome: lessons for low-resource countries. Pediatrics. 2011;127:1139-46. 